\title{
Hyperthermia therapy monitoring with guidance of B-Mode ultrasound: Study on rat breast tumor tissue
}

\author{
Maizatul Nadwa Che Aziz a, Maheza Irna Mohamad Salim a, ${ }^{\star}$, Noraida Abd Manaf a, Asnida Abd \\ Wahab a, Lai Khin Wee ${ }^{\text {b }}$, Hum Yan Chai ${ }^{\mathrm{c}}$ \\ a Department of Clinical Science, Faculty of Biosciences and Medical Engineering, Universiti Teknologi Malaysia, 81310 UTM Johor Bahru, Johor, \\ Malaysia \\ b Department of Biomedical Engineering, Faculty of Engineering, University of Malaya, 50603 Kuala Lumpur, Malaysia \\ c Department of Mechatronics and Biomedical Engineering, Lee Kong Chian Faculty of Engineering and Science, Universiti Tunku Abdul Rahman, \\ 43000 Kajang, Selangor, Malaysia \\ * Corresponding author: maheza@biomedical.utm.my
}

\section{Article history}

Received 15 October 2017

Accepted 6 December 2017

\begin{abstract}
Local hyperthermia treatment for cáncer therapy has shown increasing interest in conjunction to the other existence treatment as such chemotherapy, clinical surgery and radiation. B-Mode ultrasound has shown great potential for local hyperthermia, as it is nonionizing, convenient, and has relatively simple signal processing and it offers good spatial resolution. The aim of this study is to compare the most optimum B-Mode ultrasound parameters in normal and pathological tissue. A series of experiment was conducted on 40 female Sprague Dawley rats. 10 normal and 30 7,12-Dimethylbenz anthracene (DMBA) induced virgin female Sprague Dawley rats were kept for this study. The subjects were dissected and exposed to hyperthermia at $37^{\circ} \mathrm{C}, 40^{\circ} \mathrm{C}, 45^{\circ} \mathrm{C}, 50^{\circ} \mathrm{C}$ and $55^{\circ} \mathrm{C}$. Result shows, for mean grey scale in normal and pathological tissue, $37^{\circ} \mathrm{C}$ and $40^{\circ} \mathrm{C}$ was optimum temperature with correspond values of 188.08 and 199.26 meanwhile for pixel deviation analysis, at $45^{\circ} \mathrm{C}$ and $55^{\circ} \mathrm{C}$ the best temperature is observed in both tissue with pixel deviation of 57.27 and 57.25. Additionally, it is proven with accuracy of testing to validation data using Artificial Neural Network, ANN, about $88.89 \%$ and $81.25 \%$ was achieved.
\end{abstract}

Keywords: Local hyperthermia, cancer therapy, B-Mode Ultrasound

\section{INTRODUCTION}

Randomized trials on the benefits of hyperthermia therapy have been demonstrated over the past 20 years [1]. Notably hyperthermia is a cancer therapy that elevated the tumor to cytotoxic temperatures from $41^{\circ} \mathrm{C}$ to $45^{\circ} \mathrm{C}$ in order to aid in their control [2]. Also, hyperthermia has shown to be viable adjunct to replace the current clinical treatment including radiotherapy and chemotherapy [3]. It have been applied in several disease including breast cancer [4], glioblastoma [5], head and neck cancer [6], hepatocellular carcinoma [7] and lung cancer [8] However, other type therapy such as high temperature thermal ablations also been searched and investigated [9]. However, in 2012 there were 5,410 new breast cancer in Malaysia reported by The International Agency for Research in Cancer (GLOBOCAN), in which $50 \%$ of Malaysian women who were diagnosed with breast cancer at their early age whilst $20 \%$ of women in developed countries were diagnosed before the age of 50 [10]. Some tumors however are very aggressive and grow much faster and require immediate treatment. Tabar et al have demonstrated that survival rate is greatly improved if breast abnormalities such as breast masses are detected at the earliest stage which is concurred by Andersson and Ryden [11,12]. Hence early treatment of breast cancer is very important at this time to get rid of the cancer and perhaps it can save the live.

The lack of precised information available in guiding therapy, it has been reported a major limitation in thermal therapies [13]. In order to meet the capability and goals of current and forthcoming heating device and system, the temperature distribution is routinely measured invasively. To meet satisfactory temperature distributions in order to assess thermal dosimetry properly, the limited number of measurement distribution could be avoided [14]. With multiple heating device, it has boost the demand for temperature measurements that could provide detailed feedback about temperature distributions. Thus, it improve the ability to deliver the heat source consistently by achieving effective temperature value [15].

The application of hyperthermia therapy is now growing rapidly in medical field especially for treatment of benign and malignant solid tumors [16] as an innovative and less invasive therapy method. Hyperthermia therapy is one of the cancer treatment among surgery, chemotherapy, radiation therapy and immunotherapy [17]. It involves the changes and increase in body temperature over the threshold temperature of an organism [17]. In other words, hyperthermia is a process of delivering heat to tumor tissue until exceeding its durable temperature by some kinds of heating methods, including traditional water heating and microwave coagulation. However, during the procedure, the temperature of tissues must be kept within a suitable range [18] for ensuring the therapy can be carried out effectively and safely.

Hyperthermia treatment makes use of artificial heat, usually in the range of $40^{\circ} \mathrm{C}$ to $60^{\circ} \mathrm{C}$, from external sources to destroy cancerous cells or to prevent their further growth [19]. Also, as reported by previous study the temperature range of hyperthermia therapy is from 40 to $48^{\circ} \mathrm{C}$ and is maintained at the treated site for a period of one hour or more [20]. In some cases, hyperthermia therapy is used as adjuvant therapy 
[20] with other therapy method such as radiation to fasten tumor regression rate than radiation alone. Hyperthermia monitoring with the guided of Magnetic Resonance Imaging (MRI) is currently the gold standard in clinical setting and it is based on the concept of shift of proton resonance frequency. Its function is primarily for surgeons to perform a real-time progression assessment of in-vivo tissue necrosis [21]. Although MRI has shown to be capable in visualizing very clear and anatomically correct images, but it is found that it performance degrades during hyperthermia treatment due to small temperature interval changes [22]. In contrary to ultrasound system, A-Mode and BMode ultrasound is a good approach in monitoring thermal therapy. It is sensitive to temperature change, required simple signal processing and provide good spatial resolution [23]. It is common imaging methods used to evaluate tumors in the thyroid, breast, prostate, liver, pancreatic, ovarian, uterine and kidney, and is frequently used to guide biopsies [24]. An advantage B-Mode ultrasound to monitor temperature during hyperthermia monitoring is that this technique is relatively inexpensive, portable and can be easily employed in almost any current heating monitoring system with little concern about system compatibility. Ultrasound benefits from its portability, accessibility, low cost, non-ionizing, and compatibility with other medical equipment [21]. Technically, the monitoring approaches are based on variation in acoustic speed, [25], energy of backscattered pulsed ultrasound and acoustic nonlinear parameter imaging [26].

Therefore, this study was conducted to investigate the effectiveness of B-Mode ultrasound in monitoring hyperthermia with variation of temperature setting. The aim of this study is to develop a special transducer to be embedded to the hyperthermia system. This study will help to improve the overall hyperthermia therapy reliability to be accepted in clinical practice while assisting physicians and medical practitioners in monitoring hyperthermia treatment efficiently with minimal intervention.

\section{MATERIALS AND METHOD}

\section{Research flowchart}

Figure 1 shows a flowchart of this study in determining of B-Mode ultrasound parameter for hyperthermia monitoring. There are several stages in completing this study which include the animal handling and experimental procedure. While in stage 2, cancer induction and tissue preparation is conducted and finally in stage 3, B-Mode image processing is successfully analyzed by developing snake algorithm for determining feature extraction and finally the performance evaluation is developed using ANN. The details of each stage is further explain in the following subsection.

\section{Animal handling}

All experiment protocols dealing with animals were conducted accordance to the rules and regulations which has been approved by the institutional review board of Universiti Kebangsaan Malaysia Animal Ethics Committee (UKMAEC), Selangor Malaysia, with granted ethical endorsement \{UTM/2013/MAHEZA/17 JULY/527\}. In this study, female Sprague Dawley Rat was selected because they are easier to handle and manipulate. During adaptation period, the rats were left in the laboratory environment for one week. There are 10 normal and 30 DMBA-induced virgin female rat were kept for this study. All rats were placed in each polypropylene cage complete with enough wood shavings as their bedding, foods ad libitum and drinks. All the polypropylene cages was placed in a room at ambient temperature and controlled by automated 12 hour light/dark cycle. The weight of each rat was measured weekly, which it was in the range of $150 \mathrm{~g}$ to $330 \mathrm{~g}$.

\section{Experimental procedure}

Figure 2 shows the block diagram of heating exposure of this experiment while the real experimental set up during hyperthermia is depicted in Figure 3. B-mode ultrasonic scanner was used to capture the scanning images during the experiment. The sample tissue was heated at different temperatures located between the ultrasound transmitter and receiver at $37^{\circ} \mathrm{C}, 40^{\circ} \mathrm{C}, 45^{\circ} \mathrm{C}, 50^{\circ} \mathrm{C}$ and $55^{\circ} \mathrm{C}$ respectively. The images from $\mathrm{B}$-mode ultrasound was further processed in Matlab, offline environment for the purpose of image processing via active contour method to segment the target area of the normal and pathological tissue condition.

Stage 1: Animal Handling \& Experimental Procedure

The total of 40 female Sprague Dawley rat is used in this study. Jig is used to automate the data collection process. B-Mode monitoring system for hyperthermia therapy was developed including tissue extraction, tissue heating using water bath at different temperature to mimic hyperthermia procedure and ultrasonic parameters measurement.

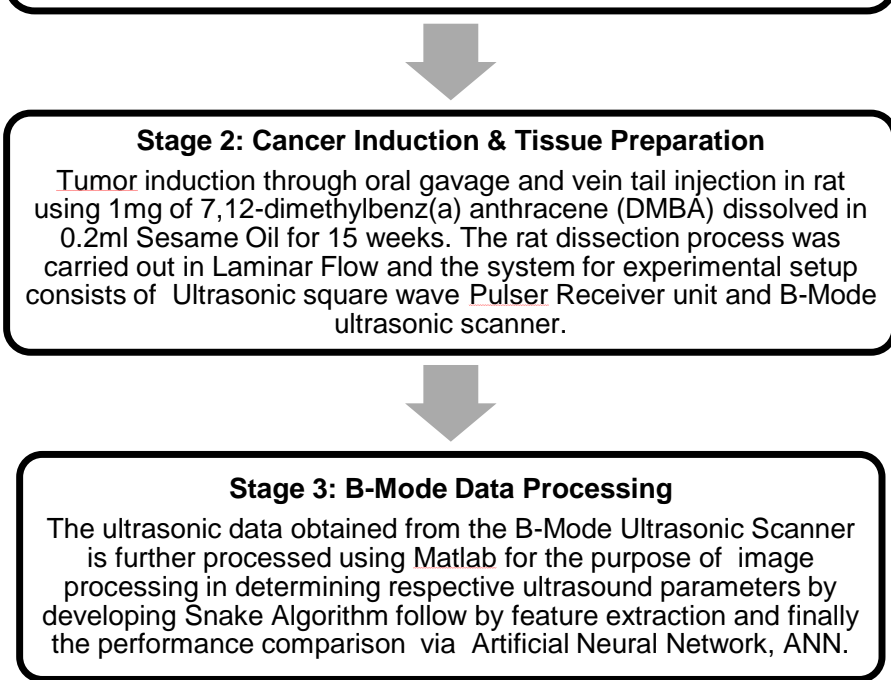

Fig 1. Flowchart of determining b-mode ultrasound parameter for hyperthermia therapy.

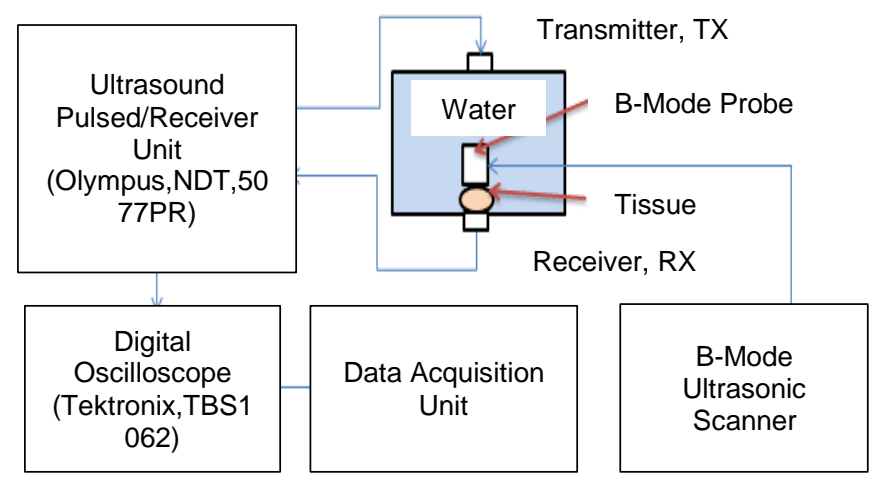

Fig 2. Block diagram of experimantal set up.

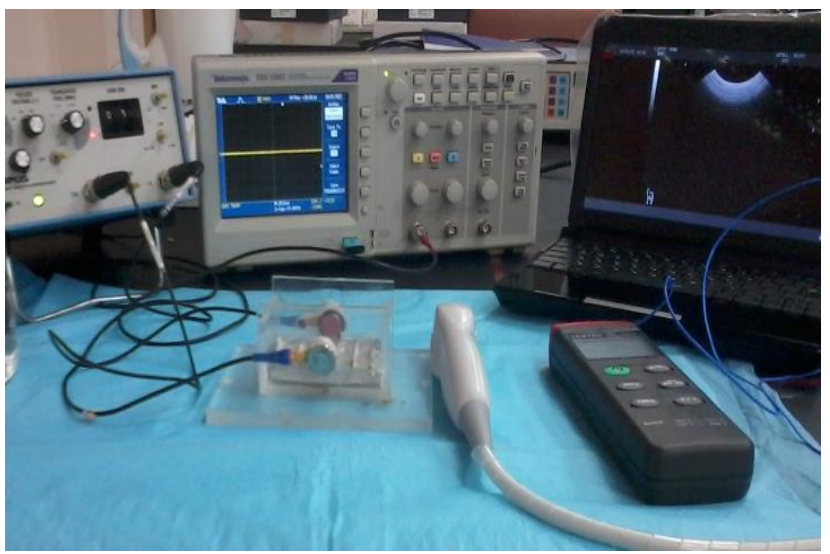

Fig 3. Experimental set up during hyperthermia therapy. 


\section{Cancer induction}

The 30 virgin female rat was treated with a single dose of 7,12Dimethylbenz anthracene (DMBA) of $1 \mathrm{mg}$, dissolved in $0.2 \mathrm{ml}$ sesame oil purchased from Sigma-Aldrich by gastric gavage/weekly for 15 weeks to initiate breast cancer. DMBA is a chemical reagent known as polyaromatic hydrocarbon for initiating the breast cancer [27,28]. As reported in clinical study, the outbred Sprague Dawley (SD) rats are among the most sensitive to carcinogen-induced mammary cancers [29].It is powerful organ-specific laboratory carcinogen purposes and immunosuppresor [30]. The use of DMBA in animal model have shown to have a closer mimic to human breast as it play a role in metabolites with capacity towards the damaging of DNA which is the prime factor in initiation of carcinogenesis as reported by previous study [6]. The formation of mammary cancer via DMBA injection can be seen clearly without other contribution factor such as hormonal restriction as demonstrated by previous researcher [31]. Hence, DMBA have been chosen as one of the chemical reagent in inducing and initiating the mammary cancer for animal model either mice or rat as it provides the effective reaction upon the injection. Mammary glands were palpated weekly for mammary tumor detection. Tumor onset, number (multiplicity) and growth were recorded when possible. The excised tumor from the subject is shown as depicted in Figure 4.

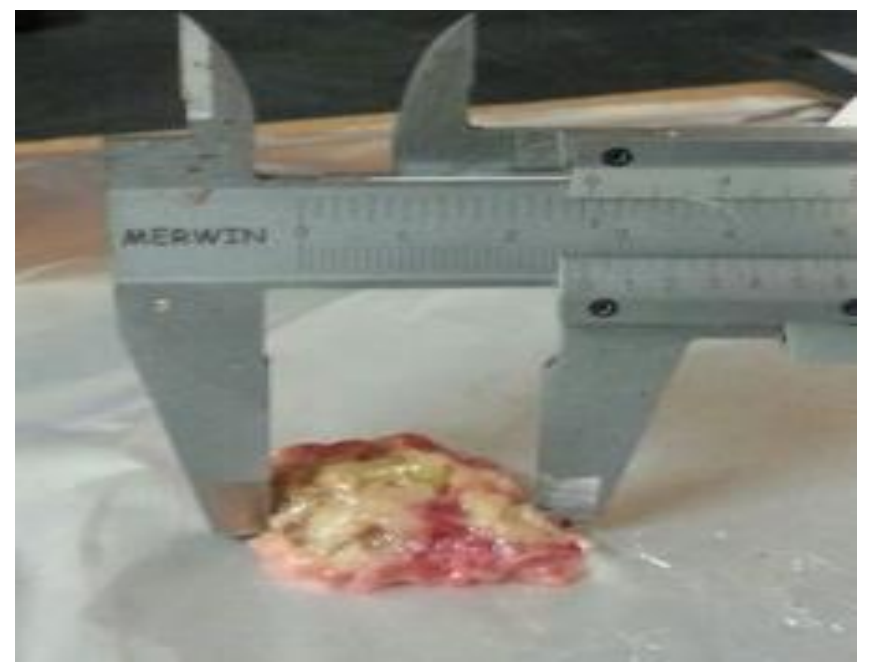

Fig. 4 Extraction of tumor from each rat.

\section{Tissue preparation}

The anesthetic drug was given to the rat intravenously via the mouse tail. Before dissection, the fur around the breast rat area was shaved. Surgery procedure was continued by harvesting normal and pathological mammary tissue to an approximately $6 \mathrm{~cm} \times 6 \mathrm{~cm}$ square shapes, with a thickness of $2.5 \mathrm{~mm}$ from each normal and DMBAinduced virgin female rat during their sleeping time. Next, the rat was killed by using drug overdose method which had been approved by animal ethics committee. The mammary tissues of normal and DMBAinduced virgin female rat was heated using water bath in the ex-vivo settings at different temperatures which are $37^{\circ} \mathrm{C}, 40^{\circ} \mathrm{C}, 45^{\circ} \mathrm{C}, 50^{\circ} \mathrm{C}$ and $55^{\circ} \mathrm{C}$ for $5-10$ minutes to mimic a real hyperthermia procedure. After the dissection, tissue sample were immediately placed inside the ice box for tissue hygiene, avoiding tissue death and maintain it structure before exposing to hyperthermia. After 5-10 minutes, the tissues was continuously exposed to $6 \mathrm{MHz}$ frequency of B-Mode.

\section{Snake algorithm}

An active contour or snake is a parametric curve expressed as $Z(s)=X(s), Y(s)$, where $0 \leq S \leq 1$. The parameter $x$ and $y$ are the coordinate of the vertices, $v$ and are functions of the normalized arc length $s$. The Snake has a dynamic behavior that deforms from an initial position and converges to the boundary of the object in the image [32]. It moves through the domain of the image by minimizing its energy function. The Esnake is defined as;

Esnake $=\int_{0}^{1}[\operatorname{Eint}(Z(s))+\operatorname{Eext}(Z(s))] d s$
The internal energy function is;

$$
\operatorname{Eint}(Z(s))=\frac{1}{2}\left\{\alpha\left|Z^{\prime}(s)\right|^{2}+\beta\left|Z^{\prime \prime}(s)\right|^{2}\right\}
$$

The internal energy function $\operatorname{Eint}(\mathrm{Z}(\mathrm{s}))$ is computed based on the local shape of the curve $\mathrm{v}(\mathrm{s})$, and is responsible in determining the continuity and the smoothness of the curve. The parameter $\alpha$ and $\beta$ are the coefficient of the internal energy function. The parameter $\alpha$ is the elasticity parameter. For a large value of the curve becomes very straight between two points. The parameter $\beta$ is the rigidity parameter and for a large value of $\beta$ the curve becomes smooth. On the other hand, the external energy function Eext $(\mathrm{Z}(\mathrm{s}))$ is derived based on the image information and it drives the curve to the boundary of the object [33]. Different types of Snakes use different type of external energy function. By calculus of variation, Equation (1) is minimized by solving the associate Euler's Equation as follows;

$$
-\alpha Z^{\prime \prime}(s)+\beta Z^{(4)}(s)+\nabla \operatorname{Eext}(Z(s))=0
$$

In B-Mode images, for the purpose of feature extraction, firstorder statistical parameters on mean grayscale (MSG) and pixel deviation of the grayscale are measured using grey level histogram method [24]. Firstly the calculation of the occurrence of probability grey scale could be done and it can be denoted as;

$$
P(r k)=\frac{n k}{n}
$$

where $n$ is the total number of the pixels in an image. Therefore,

$$
\sum_{k=0}^{L-1} P(r k)=1
$$

The MGS is the mean of the gray scale for pixels in an image. This can be calculated as;

$$
M G S=\sum_{k=0}^{L-1} r k \cdot P(r k)
$$

The STD measures the dispersivity of the gray scale from the MGS. It can be calculated as;

$$
S T D=\sum_{k=0}^{L-1}(r k-M G S) \cdot P(r k)
$$

\section{B-Mode feature extraction}

All the images collected from B-Mode ultrasound were saved in the form of JPEG. The data from this modality was further analysed in Matlab offline environment. The image processing was done in which the image were first loaded in Matlab for pre-processing and enhancement purposes. Next, the image were cropped for the purpose of removing unwanted region to be segmented. The cropping image later were consider as finalized image for plotting the coordinate on the image itself. The coordinate were plotted clockwise on the image accordingly. Later, the segmentation processing via snake start to process for indication the boundary of targeted region. Finally, the boundary of targeted area were identified and segmented. The outcomes of every segmented image were saved for further statistical analysis calculation and performance evaluation such as mean grey scale of pixel intensity and pixel deviation of segmented boundary. Figure 5 shows the outcome of image segmentation workflow in this study. Firstly, the image were load in Matlab for pre-processing including image enhancement, contrast adjustment and cropping as shown in figure (a). In figure (b), it shows the image with initial contour, by means the image after plotting the coordinates surrounded the boundary. The image of external energy were shown in figure (c) by means of translating from initial contour meanwhile in figure (d) is the outcome after snake movement identification of boundary. Finally, the segmented region were shown as in figure (e) showing the area of interest successfully segmented. 


\section{Development of Artificial Neural Network (ANN)}

An artificial neural network B-Mode for breast cancer classification was developed in this study. There are four stages in this ANN development. In the first stage, data massaging and data sampling were processed in a spreadsheet format in Microsoft excel. A total of 130 of B-Mode data were obtained during the experiment and were used as input and output of ANN. The input data were divided into three different group namely training $(\mathrm{N}=78)$, testing $(\mathrm{N}=36)$ and validation $(\mathrm{N}=16)$. The range of target output is from 0 to 1 , the value of ' 1 ' indicating normal tissue condition while ' 0 ' indicates abnormal tissue condition. The mean grey scale, pixel deviation, variance and area are the input parameters that were fed into ANN development. The data were prepared separately in spreadsheet in Microsoft Excel and then were exported into the Matlab workspace for further processing for training, testing and validation purposes.

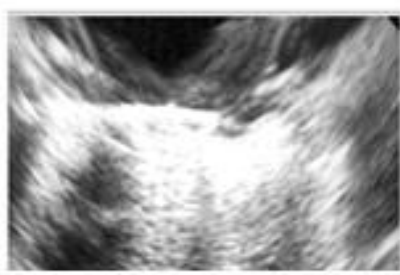

a) Pre-processing

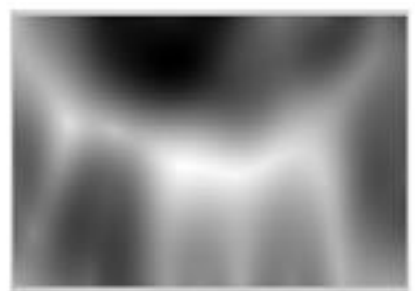

c) The external energy

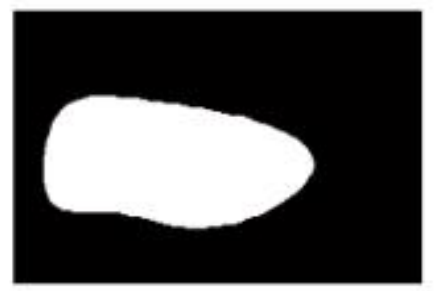

e) Segmented Boundary

Fig 5. Active contour segmentation workflow.

\section{RESULTS AND DISCUSSION}

\section{Mean grey scale and pixel deviation of pixel intensity}

The result of this study were summarized as in Figure 4 and Figure 5 respectively. Figure 6 and 7 shows the average mean of pixel intensity and pixel deviation of B-Mode images in normal and pathological tissue. The tissue was heated at various temperatures before and after hyperthermia. In Figure 5, for normal tissue condition, the highest mean grey scale of pixel intensity was observed at temperature value of $37{ }^{\circ} \mathrm{C}$ with a pixel intensity value of 188.08 while the lowest mean grey scale of pixel intensity was 183.07 at $55^{\circ} \mathrm{C}$. The mean grey scale of pixel intensity in pathological tissue of 192.15, 199.26, 195.10, 195.82 and 193.18 was observed at temperature of $37{ }^{\circ} \mathrm{C} 40^{\circ} \mathrm{C}, 45^{\circ} \mathrm{C}, 50^{\circ} \mathrm{C}$ and $55^{\circ} \mathrm{C}$ individually. In summary, in normal tissue condition, a temperature value of $37{ }^{\circ} \mathrm{C}$ was chosen as an optimum temperature dependent seems the mean grey scale of pixel intensity is more pronounce than the other values meanwhile a temperature value of $40{ }^{\circ} \mathrm{C}$ was chosen as an optimum temperature dependent in pathological tissue as it produced the highest pixel intensity for B-Mode analysis with respect to the mean of pixel intensity in monitoring hyperthermia therapy for both tissue condition.

Based on Figure 6, the average pixel deviation at body temperatures in normal tissue which is before hyperthermia was 55.74 . Meanwhile, the average pixel deviation in normal tissue at $40^{\circ} \mathrm{C}, 45^{\circ} \mathrm{C}$, $50^{\circ} \mathrm{C}$ and $55^{\circ} \mathrm{C}$ after hyperthermia was analyzed with correspond values of 56.84, 57.27, 53.49 and 54.79 individually .From statistical data analysis also, the average pixel deviation of B-Mode images in pathological tissue at $37{ }^{\circ} \mathrm{C}$ was found to be 53.03. After hyperthermia, the highest pixel deviation was analyzed at temperature value of $55^{\circ} \mathrm{C}$ with a correspond value of 57.25 while at temperature values of $40{ }^{\circ} \mathrm{C}$, the average pixel deviation tends to be 48.89 which indicate the least pixel deviation as compared to the others pixel deviation values. Hence, in comparison for both condition, temperature value of $45^{\circ} \mathrm{C}$ and $55^{\circ} \mathrm{C}$ was chosen as optimum temperature dependent of normal and pathological tissue condition for hyperthermia therapy monitoring with respect to average of pixel deviation of both tissue condition. Several studies have reported that the texture features of B-mode ultrasonic images have certain relationships with tissue temperature [34]. Pousek et all found that both the mean of the gray scale (MGS) and gradient scale value increased with tissue temperature. They also showed that the feasibility of temperature monitoring is high for B-mode ultrasonic image processing in hyperthermia [35]. Wu et al1 proved the significant difference in the gray value of treated regions in a B-mode image before and after heating [36].

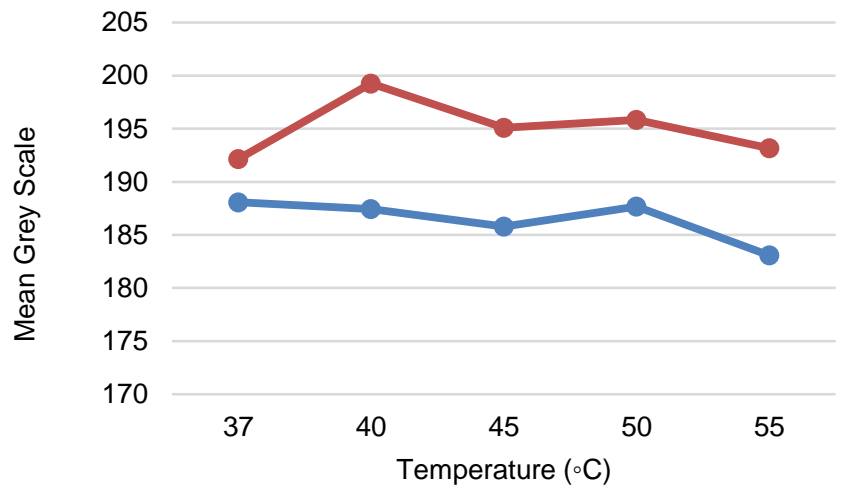

$\longrightarrow$ Normal Tissue $\longrightarrow$ Pathological Tissue

Fig 6. Mean grey scale vs temperature in normal and pathological tissue.

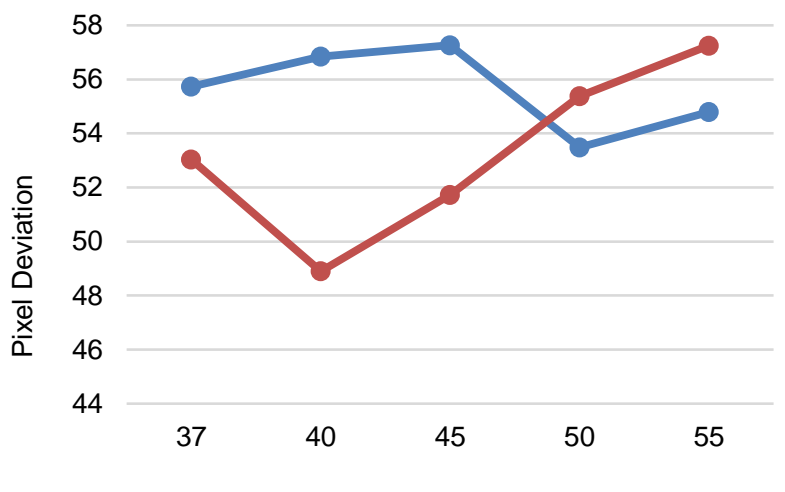

Temperature $(\circ \mathrm{C})$

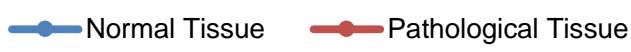

Fig 7. Pixel deviation vs temperature for normal and pathological tissue.

\section{Correlation plot between mean grey scale and pixel deviation}

Figure 8 illustrate the correlation between mean grey scale and pixel deviation of B-Mode ultrasound obtained from the experiments. 
Mean grey scale level changes against pixel deviation is more sensitive in pathological tissue samples with positive correlation coefficient of 0.6428 , while it records a value of 0.0671 when associated with pixel deviation changes in normal tissue samples. This particular finding specifies that as the hyperthermia treatment is conducted, the image occurring in the pathological tissue can be monitored using mean grey scale level, prior to further biological changes taking place within the same tissue.

However, the investigation on the techniques by using those ultrasonic features still on going. Fortunately, B-mode ultrasonic images can be obtained during monitoring thermal therapy procedure as a whole [37]. In addition, the technique using B-Mode images is frequently applied and valuable. The formation of B-Mode images caused by ultrasonic echoes of gray level modulation from the tissue. Upon the procedure, the coagulation of tissue will cause some changes in the acquired B-Mode images [38]. In clinical environment, the monitoring approaches for tissue temperature via B-Mode images has been extensively and widely searched and conducted [39]. Ren et al., have conducted experimental study in vitro for porcine livers, the result showed that the temperature values of tissue had close relationship with the features power spectra density, gradient scale value and MGS [40]. Parkkinen and others [41] showed that grey-level co-occurrence matrices potentially to be used on the different interpixel distances to disclose about periodicity in the feature of B-Mode images. The gathered finding on the B-Mode texture feature analysis in hyperthermia monitoring shows great therapeutic achievement, though this modality reported by investigators, its experiences certain limitation including image contrast and motion artefacts [42-47].

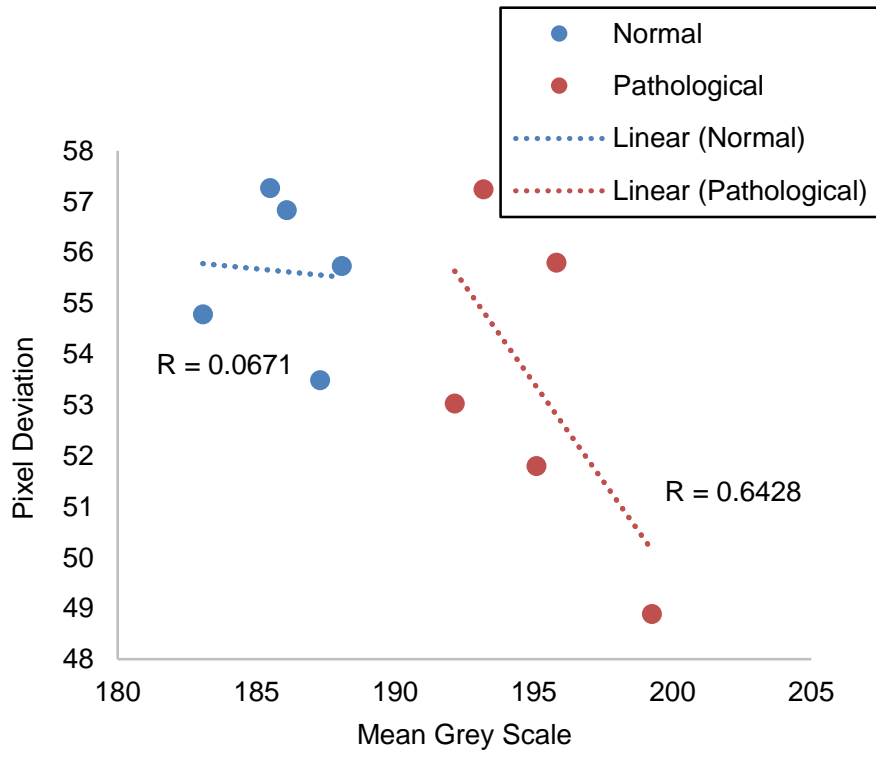

Fig 8. Sensitivity plot (pixel deviation against mean grey scale).

\section{CONCLUSION}

In summary, in this study the feasibility of B-Mode ultrasound for real time and accurate thermal therapy monitoring method was investigated. The temperature value of $37{ }^{\circ} \mathrm{C}$ and $40^{\circ} \mathrm{C}$ was more pronounce in normal and pathological tissue condition for calculation mean of pixel intensity, meanwhile, for average pixel deviation, temperature value of $45^{\circ} \mathrm{C}$ and $55^{\circ} \mathrm{C}$ was chosen as the best temperature dependent of normal and pathological tissue condition. This study was revealed in which the calculation of all parameters of B-Mode including mean grey scale of pixel intensity and average pixel deviation via active contour algorithm was able to segment and it is sensitive in tissue structure with variation of temperatures during hyperthermia monitoring. It was proven with the percentage accuracy of testing to validation data using artificial neural network, about $88.89 \%$ and $81.25 \%$ was achieved and the success of this study will help to provide a simple and safe method in monitoring local hyperthermia therapy using B-Mode ultrasound and can be widely accepted in clinical environment.

\section{ACKNOWLEDGEMENT}

The authors would like to express gratitude to the Malaysian Ministry of Higher Education (MOHE) and Universiti Teknologi Malaysia for research grant (R.J130000.7845.4F274) and facility.

\section{REFERENCES}

[1] van der Zee, J. (2002). Heating the patient: a promising approach? Annals of Oncology, 13(8), 1173-1184.

[2] Dewhirst, M. W., Prosnitz, L., Thrall, D., Prescott, D., Cleff, S., Charles, C., Macfall, J., Rosner, G., Samulski, T., Gillette, E., LaRue, S. (1997) Hyperthermic treatment of malignant diseases: Current status and a view toward the future. Seminars in Oncology, 24(6), 616-625.

[3] Overgaard, J., Gonzales, D., Hulshof, M., Arcangeli, G., Dahl, O., Mella, O., Bentzen, S. (1996). Hyperthermia as an adjuvant to radiation therapy of recurrent or metastatic malignant melanoma. A multicenter randomized trial by the European Society for Hyperthermic Oncology. International Journal of Hyperthermia, 12(1.), 3-20.

[4] Vernon, C. C., Hand, J. W., Field, S. B., Machin, D., Whaley, J. B., van der Zee, J., van Putten, W. L., van Rhoon, G. C., van Dijk, J. D., González González, D., Liu, F. F., Goodman, P., Sherar, M. (1996). Radiotherapy with or without hyperthermia in the treatment of superficial localized breast cancer: Results from 5 randomized controlled trials. International Collaborative Hyperthermia Group. International Journal of Radiation Oncology, Biology and Physic, 35(4), 731-744.

[5] Sneed, P. K., Stauffer, P. R., McDermott, M. W., Diederich, C. J., Lamborn, K. R., Prados, M. D., Chang, S., Weaver, K. A., Spry, L., Malec, M. K., Lamb, S. A., Voss, B., Davis, R. L., Wara, W. M., Larson, D. A., Phillips, T. L., Gutin, P. H. (1998). Survival benefit of hyperthermia in a prospective randomized trial of brachytherapy boost + / hyperthermia for glioblastoma multiforme. International Journal of Radiation Oncology, Biology and Physic, 40(2), 287- 295.

[6] Moffat, F. L., Rotstein, L. E., Calhoun, K., Langer, J. C., Makowka, L., Ambus, U., Palmer, J. A., Campbell, A., Howard, V., Mikkelsaar, R. (1984). Palliation of advanced head and neck cancer with radiofrequency hyperthermia and cytotoxic chemotherapy. Cancer Journal Surgery, 27(1), 38-41.

[7] Kim, S. K., Lim, H. K., Kim, Y. H., Lee, W. J., Lee, S. J., Kim, S. H., Lim, J. H., Kim, S. A. (2003). Hepatocellular carcinoma treated with radiofrequency ablation: Spectrum of imaging findings. Radiographics,.23(1), 107-121.

[8] Simon, C. J., Dupuy, D. E., DiPetrillo, T. A., Safran, H. P., Grieco, C. A., Ng, T., Mayo-Smith, W. W. (2007). Pulmonary radiofrequency ablation: long-term safety and efficacy in 153 patients. Radiology, 243(1), 268-275.

[9] Hynynen, K., Chung, A., Fjield, T., Buchanan, M., Daum, D., Colucci, V., Lopath, P., Jolesz, F. (1996). Feasibility of using ultrasound phased arrays for MRI monitored noninvasive surgery. IEEE Transactions on Ultrasonics, Ferroelectrics, and Frequency Control, 43(6), 1043-1053.

[10] Ferlay, J., Soerjomataram, I., Ervik, M., Dikshit, R., Eser, S., Mathers, C., Rebelo, M., Parkin, D. M., Forman, D., Bray, F. (2013) GLOBOCAN 2012 Cancer incidence and mortality worldwide: IARC Cancerbase No.11. Lyon, France: International Agency for Research on Cancer. Available from: http://globocan.iarc.fr.

[11] Tabar, L., Vitak, B., Chen, H. H., Yen, M. F., Duffy, S. W., Smith, R. A (2001). Beyond randomized trials: Organized mammographic screening substantially reduces breast carcinoma mortality. Cancer, 91(9), 1724 1731 .

[12] Andersson, I., and Ryden, S. (2001). Early detection and prevention: Benefits, costs and limitations of screening. In Tobias, J. S., Houghton, J., and Henderson, I. C. (eds.), Breast Cancer: New horisons in research and treatment (pp. 105-117). London: Arnold.

[13] Dewhirst, M., Sim, D., Sapareto, S., Coner, W. (1984). Importance of minimum tumor temperature in determiningearly and long-term responses of spontaneous canine and feline tumors to heat and radiation. Cancer Research, 44(1), 43-50. 
[14] Myerson, R., Perez, C., Emami, B., Straube, W., Kuske, R., Leybovich, L., VonGerichten, D. (1990). Tumor control in longterm survivors following superficial hyperthermia. International Journal of Radiation Oncology, Biology \& Physics, 18(5), 1123-1129.

[15] Underwood, H. R., Burdette, E. C., Ocheltre, K. B., Magin, R. L., (1987) A multielement ultrasonic hyperthermia applicator with independent element control. International Journal of Hyperthermia, 3(3), 257-267.

[16] Kennedy, J. E. (2005). High-intensity focused ultrasound in the treatment of solid tumours. Nature Reviews: Cancer, 5(4), 321-327.

[17] Dewhirst, M. W., Gibbs, F. A. Jr., Roemer, R. B., Samulski, T. V. (2000) Hyperthermia. In: Gunderson, L. L., Tepper J. E. (eds.). Clinical Radiation Oncology ( $1^{\text {st }}$ ed.) Chapter 14 (pp. 256-82). New York: Churchill Livingstone.

[18] Bailey, M. R., Khokhlova, V. A., Sapozhnikov, O. A., Kargl, S. G., Crum, L. A. (2003). Physical mechanisms of the therapeutic effect of ultrasound (A review). Acoustical Physics, 49(4), 369-388.

[19] Chicheł, A., Skowronek, J., Kubaszewska, M., Kanikowski, M. (2007). Hyperthermia - Description of a method and a review of clinical applications. Reports of Practical Oncology and Radiotherapy, 12(5), 267-275.

[20] Sneed, P. K., Stauffer, P. R., Li, G. C., Stege, G. J. J. (2004). Hyperthermia In Leibel, S. A., Phillips, T. L. (eds.). Textbook of Radiation Oncology (2nd ed.) Chapter 70 (pp. 1569-1596). Saunders.

[21] McDannold, N. (2005). Quantitative MRI-based temperature mapping based on the proton resonant frequency shift: Review of validation studies. International Journal of Hyperthermia, 21(6), 533-546.

[22] Zhou, Y. F., (2011). High intensity focused ultrasound in clinical tumor ablation. World Journal of Clinical Oncology, 2(1), 8-27.

[23] Bazan, I., Vazquez, M., Ramos, A., Vera, A., Leija, L. (2009). A performance analysis of echographic ultrasonic techniques for noninvasive temperature estimation in hyperthermia range using phantoms with scatterers. Ultrasonics, 49(3), 358-376.

[24] Damianou, C. A., Sanghvi, N. T., Fry, F. J., MaassMoreno, R. (1997) Dependence of ultrasonic attenuation and absorption in dog soft tissues on temperature and thermal dose. Journal of the Acoustical Society of America, 102(1), 628-634.

[25] Liu, X., Gong, X., Yin, C., Li, J., Zhang, D. (2008). Noninvasive eatimation of temperature elevations in biological tissues using acoustic nonlinearlity parameter imaging. Ultrasound in Medicine and Biology, 34(3), 414-424.

[26] Ribault, M., Chapelon, J. Y., Cathignol, D., Gelet, A. (1998). Differential attenuation imaging for the characterization of high intensity focused ultrasound lesions. Ultrasonic Imaging, 20(3), 160-177.

[27] Gear, R. B., Yan, M., Schneider, J., Succop, P., Heffelfinger, S. C., Clegg, D.J., (2007). Charles river sprague dawley rats lack early age-Dependent susceptibility to DMBA-Induced mammary carcinogenesis. International Journal of Biological Sciences, 3(7), 408-416.

[28] Russo, I. H., Russo, J. (1978). Developmental stage of the rat mammary gland as determinant of its susceptibility to 7,12dimethylbenz(a)anthracene. Journal of the National Cancer Institute, 61(6), 1439-1442.

[29] Russo, I. H., Russo, J. (1996). Mammary gland neoplasia in long-term rodent studies. Environmental Health Perspectives, 104(9), 938-966.

[30] Miyata, M., Furukawa, M., Takahashi, K., Gonzalez, F. J., Yamazoe, Y. (2001). Mechanism of 7, 12-dimethylbenz[a]anthracene-induced immunotoxicity: Role of metabolic activation at the target organ. Japanese Journal of Pharmacology, 86(3), 302-309.
[31] Muggins, C., Briziarelli, G., and Button, H., Jr. (1959). Rapid induction of mammary carcinoma in the rat and the influence of hormones on the tumors. Journal of Experimental Medicine, 109(1), 25-42.

[32] Jumaat, A. K., Wan Abdul Rahman, W. EZ., Ibrahim, A., Mahmud, R. (2010). Segmentation of masses from breast ultrasound images using parametric active contour algorithm. Procedia Social and Behavioral Sciences, 8, 640-647.

[33] Kass, M., Witkin, A., Terzopoulos, D. (1986). Snakes: Active contour models. International Journal of Computer Vision, 1(4) 321-331.

[34] Simon, C., Van Baren, P., Ebbini, E. S. (1998). Two-dimensional temperature estimation using diagnostic ultrasound. IEEE Trans Ultrason Ferroelectr Freq Control, 45(4), 1088-1099.

[35] Pousek, L., Jelinek, M., Storkova, B., Novak, P. (2006). Noninvasive temperature monitoring using ultrasound tissue characterization method. In: Proceedings of the 2006 Information Technology Interfaces Conference. Piscataway, NJ: Institute of Electrical and Electronics Engineers, 219-224.

[36] Wu, X., Qian, S. Y., Sun, F. C., Zhang, J. (2007). Study of noninvasive temperature measurement based on B-mode ultrasonic image processing. Computer Engineering and Applications, 43, 178-179.

[37] Chunlan, Y., Hao, Z., Shuicai, W., Yanping, B., Hongjian, G. (2010). Correlations between B-Mode ultrasonic image texture features and tissue temperature in microwave ablation. Journal of Ultrasound in Medicine, 29(12), 1787-1799.

[38] Xu, T., Ye, Z. Q., Cai, W. M. (2006). Texture analysis methods used in B scan liver images. Foreign Medical Science Fascicle Biomedical Engineering, 29(4), 228-230.

[39] Udomchai, T., Quan, C., Varghese, T. (2005) Ultrasonic noninvasive temperature estimation using echo shift gradient maps: simulation results. Ultrason Imaging, 27(3), 166-180.

[40] Ren, X. Y., Wu, S. C., Zeng, Y. (2008). Experimental study for noninvasive monitoring of hyperthermia based on B-mode ultrasonic tissue characterization. Journal of Beijing University Technology, 34, 90 96.

[41] Parkkinen, J. and Oja, E. (1990). Detecting texture periodicity from the cooccurrence matrix, Pattern Recognition Letters, 11(1), 43-50.

[42] Hill, C. R., ter Haar, G. R. (1995). High intensity focused ultrasound potential for cancer treatment. The British Journal of Radiology, 68(816), 1296-1303.

[43] Hsiao, Y. S. (2013). Focused ultrasound thermal therapy monitoring using ultrasound, infrared thermal, and photoacoustic imaging techniques (Ph.D. dissertation at the University of Michigan).

[44] Hynynen, K., Vykhodtseva, N.I., Chung, A., Sorrentino, V., Colucci, V., Jolesz, F.A. (1997). Thermal effects of focused ultrasound on the brain: Determination with MR imaging. Radiology, 204(1), 247-253.

[45] Rangraz, P., Behnam, H., Tayakkoli, J., Nakagami. (2014). Imaging for detecting thermal lesions induced by high-intensity focused ultrasound in tissue. Proceeding of the Institution of Mechanical Engineers, Part H: Journal of Engineering in Medicine, 228(1),19-26.

[46] Haar, G.R. (1995). Ultrasound focal beam surgery. Ultrasound in Medicine and Biology, 21(9), 1089-1100.

[47] Zhang, S., Wan, M., Zhong, H., Xu, C., Liao, Z., Liu, H., Wang, S. (2009). Dynamic changes of integrated backscatter, attenuation coefficient and bubble activities during high intensity focused ultrasound (HIFU) treatment. Ultrasound in Medicine and Biology, 35(11), 1828-1844. 